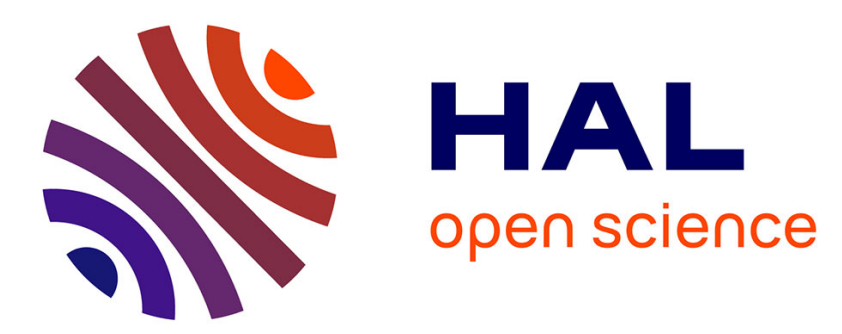

\title{
Stress- and growth-induced anisotropic birefringences in garnet films
}

A.N. Ageev, O.G. Rutkin, A.S. Trifonov, V.B. Kravtchenko, L.M. Filimonova, H. Le Gall, J.M. Desvignes

\section{- To cite this version:}

A.N. Ageev, O.G. Rutkin, A.S. Trifonov, V.B. Kravtchenko, L.M. Filimonova, et al.. Stress- and growth-induced anisotropic birefringences in garnet films. Revue de Physique Appliquée, 1985, 20 (11), pp.753-757. 10.1051/rphysap:019850020011075300 . jpa-00245390

\section{HAL Id: jpa-00245390 https://hal.science/jpa-00245390}

Submitted on 1 Jan 1985

HAL is a multi-disciplinary open access archive for the deposit and dissemination of scientific research documents, whether they are published or not. The documents may come from teaching and research institutions in France or abroad, or from public or private research centers.
L'archive ouverte pluridisciplinaire $\mathbf{H A L}$, est destinée au dépôt et à la diffusion de documents scientifiques de niveau recherche, publiés ou non, émanant des établissements d'enseignement et de recherche français ou étrangers, des laboratoires publics ou privés. 


\title{
REVUE DE PHYSIQUE APPLIQUÉE
}

Revue Phys. Appl. 20 (1985) 753-757

NOVEMBRE 1985, PAGE 753

Classification

Physics Abstracts

$78.65-78.20 \mathrm{~F}$

\section{Stress- and growth-induced anisotropic birefringences in garnet films}

\author{
A. N. Ageev $(*)$, O. G. Rutkin $(*)$, A. S. Trifonov $(*)$, \\ V. B. Kravtchenko $\left({ }^{* *}\right)$, L. M. Filimonova $\left({ }^{* *}\right)$, H. Le Gall $\left({ }^{+}\right)$and J. M. Desvignes $\left({ }^{+}\right)$ \\ (*) A. F. Ioffe Physico-Technical Institute, Politechnicheskaya, 26, Leningrad, U.S.S.R. \\ (**) Institute of Radiotechnic and Electronics, 103907 Karl Marx Avenue 18, Moscow, U.S.S.R. \\ $\left(^{+}\right)$C.N.R.S., Laboratoire de Magnétisme et d'Optique des Solides, 92190 Meudon, France
}

(Reçu le 31 juillet 1984, révisẻ le 17 juillet 1985, accepté le 30 juillet 1985)

\begin{abstract}
Résumé. - A partir de mesures de propagation guidée de lumière dans des films de grenat ferrimagnétiques substitués par des ions de terres rares et de bismuth, on montre que la biréfringence optique $\Delta n$ présente des contributions importantes $\Delta n_{\sigma}$ et $\Delta n_{\mathrm{G}}$ associées aux biréfringences induites par contraintes élastiques (photoélastique) et par croissance par épitaxie qui dépendent de la composition chimique, de la température de croissance $T_{G}$ d'épitaxie et de l'orientation des substrats. La dépendance de $\Delta n_{\sigma}$ avec $T_{\mathrm{G}}$ est directement associée aux variations des coefficiènts de ségrégation des différents ions en substitution dans le grenat, ce qui change leur taux de substitution et partant, les écarts des paramètres de maille entre les films et leurs substrats. Par contre $\Delta n_{G}$ apparaît comme indépendant de $T_{\mathrm{G}}$. Des comportements anisotropes de $\Delta n_{\sigma}$ ont été par ailleurs observés dans les films de $\mathrm{Bi}_{7} \mathrm{YIG}$ de plan (110). Les différentes contributions à $\Delta n$ ont été déterminées et sont discutées à partir de modèles théoriques.
\end{abstract}

\begin{abstract}
From optical wave-guide experiment in rare-earth and bismuth-substituted iron garnet films, it is shown that the optical birefringence $\Delta n$ presents important contributions $\Delta n_{\sigma}$ and $\Delta n_{\mathrm{G}}$ arising from stress-induced (photoelastic) and growth-induced birefringences which depend on the chemical composition, growth temperature $T_{\mathrm{G}}$ and orientation of the film. The dependence of $\Delta n_{\sigma}$ on $T_{\mathrm{G}}$ is directly associated with the variation of the segregation coefficients of the different ions substituted in the garnet which changes their content and therefore the lattice mismatch between the films and the substrates. On the other hand $\Delta n_{G}$ seems to be independent on $T_{G^{*}}$ In (110)-oriented Bi-YIG films anisotropic behaviours have been observed for $\Delta n_{\sigma}$. The different contributions to $\Delta n$ are determined and discussed from theoretical models.
\end{abstract}

\section{Introduction.}

Nonreciprocal device in integrated optics imply high value for the maximum TE-TM modes conversion ratio $R_{\mathrm{m}}=K^{2} /\left[K^{2}+(\Delta \beta / 2)^{2}\right]$ where $K$ and $\Delta \beta$ are the coupling coefficient and the phase mismatch between the modes [1]. Full conversion is obtained $\left(R_{\mathrm{m}}=1\right)$ when $\Delta \beta=0$ which is not the case for most of epitaxial garnet films where an effective phase mismatch $\Delta n_{\mathrm{e}}=n_{\mathrm{TE}}-n_{\mathrm{TM}}$ is observed even in optically isotropic films. Different methods have been proposed to achieve high mode conversion efficiencies in magnetooptic waveguides [2]. As shown in figure 1, $\Delta \beta=0$ when the TE and TM mode presents a crossing point which is the case in optically anisotropic films with different asymptotic values $n_{x}$ and $n_{z}$ of the effective modes indices. In addition to the linear magnetic birefringence or Cotton-Mouton effect, Hepner et al. have suggested the use the stress-induced birefringence $\Delta n_{\sigma}=n_{\mathrm{TE}}^{\sigma}-n_{\mathrm{TM}}^{\sigma}$ [3] to produce anisotropic film and therefore modes degeneracy. Conversion ratios higher than $97 \%$ have been demonstrated by Courtois et al. [4] in films whose the stress-induced birefringence $\Delta n_{\sigma}$ cancels the isotropic phase mismatch $\Delta n_{\mathrm{i}}$ such as $\Delta n_{\mathrm{e}}=\Delta n_{\mathrm{i}}+\Delta n_{\sigma}=0$.

In the present paper we have determined the different contributions to the TE-TM modes phase mismatch in rare earth and bismuth-substituted YIG films grown 


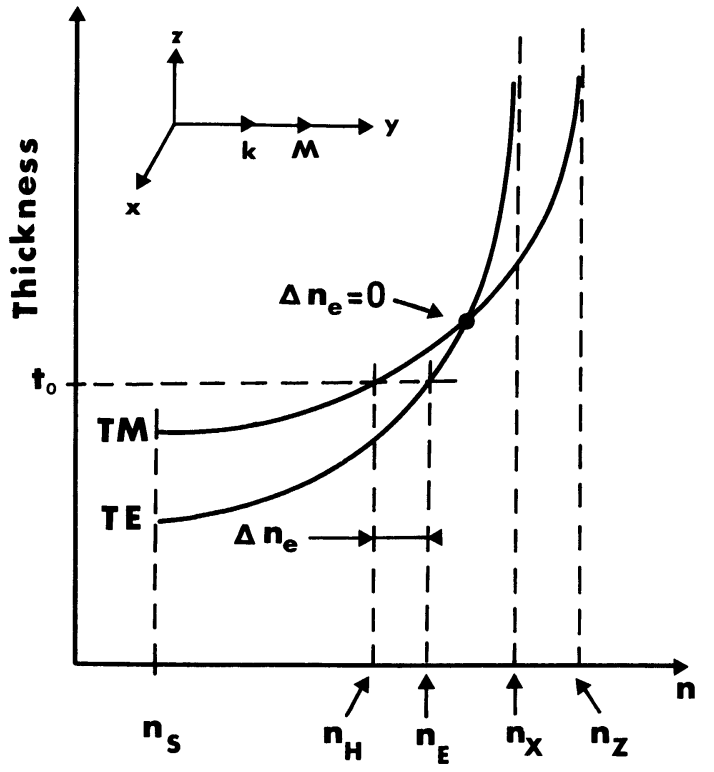

Fig. 1. - Effective TE and TM modes indices in optically anisotropic film.

from LPE method on (111)- and (110)-oriented $\mathrm{Gd}_{3} \mathrm{Ga}_{5} \mathrm{O}_{12}$ (GGG) substrates. It is shown that the phase mismatch can be described by four main terms associated respectively with isotropic $\Delta n_{\mathrm{i}}$ and anisotropic $\Delta n_{\mathrm{a}}$ contribution such as :

with

$$
\left.\begin{array}{l}
\Delta n_{\mathrm{e}}=\Delta n_{\mathrm{i}}+\Delta n_{\mathrm{a}} \\
\Delta n_{\mathrm{a}}=\Delta n_{\sigma}+\Delta n_{\mathrm{G}}+\Delta n_{\mathrm{CM}}
\end{array}\right\}
$$

where $\Delta n_{\mathrm{G}}$ and $\Delta n_{\mathrm{CM}}$ are the growth-induced birefringence and the linear magnetic birefringence or Cotton-Mouton effect. As discussed later $\Delta n_{\mathrm{CM}}$ is one or two orders smaller than $\Delta n_{\sigma}$ and $\Delta n_{\mathrm{G}}$ and therefore the main contributions to the anisotropic phase-mismatch arise from the photoelastic and the growth-induced birefringence.

The relative values of the different contributions are strongly dependent on the chemical composition, the growth temperature $T_{\mathrm{G}}$ and the film orientation. The important contributions to $\Delta n_{\mathrm{e}}$ from $\Delta n_{\sigma}$ and $\Delta n_{\mathrm{G}}$ are determined and discussed from theoretical models.

\section{Results.}

Film of different compositions corresponding to the systems $(\mathrm{YbPr})_{3}(\mathrm{FeGa})_{5} \mathrm{O}_{12}$ and $(\mathrm{BiGdYbY})_{3}(\mathrm{FeAl})_{5}$ $\mathrm{O}_{12}$ were grown from usual LPE method on (111)and (110)-oriented GGG substrates respectively. The optical phase mismatch, the unit cell parameter $a_{\perp}$ of the films, the deformation difference $\left(u_{\perp}-u_{\|}\right)=$ $\left(a_{\mathrm{s}}-a_{\perp}\right) / a_{\mathrm{s}}$, where $a_{\mathrm{s}}$ is the lattice parameter of the substrate, and the Curie temperature $T_{\mathrm{c}}$ have been determined for different growth temperature $T_{G}$ as shown on figures 2 to $4 . a_{\perp}$ is determined from X-ray technique with accuracy better than $5 \times 10^{-4} \AA$.

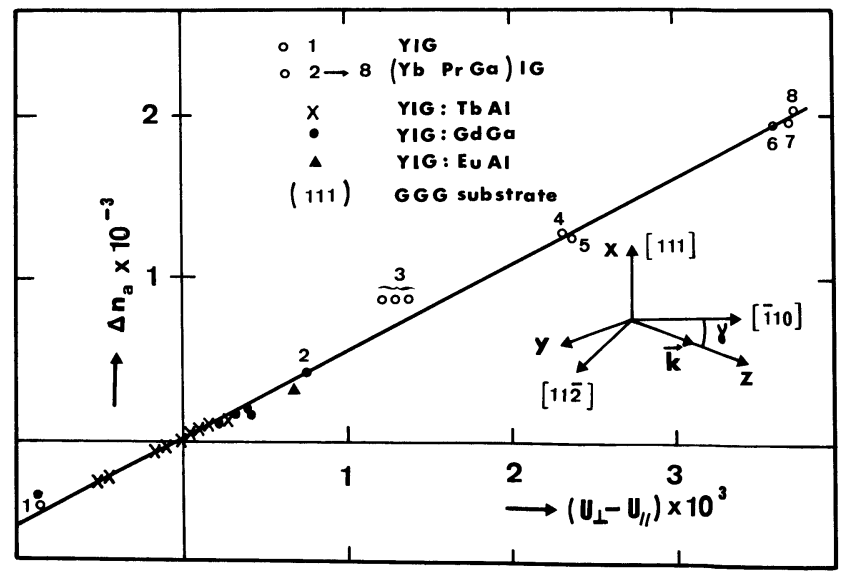

Fig. 2. - Deformation dependence of the anisotropic birefringence $\Delta n_{\mathrm{a}}=\left(n_{\mathrm{TM}}^{\mathrm{a}}-n_{\mathrm{TE}}^{\mathrm{a}}\right)$ in (111)-oriented films.

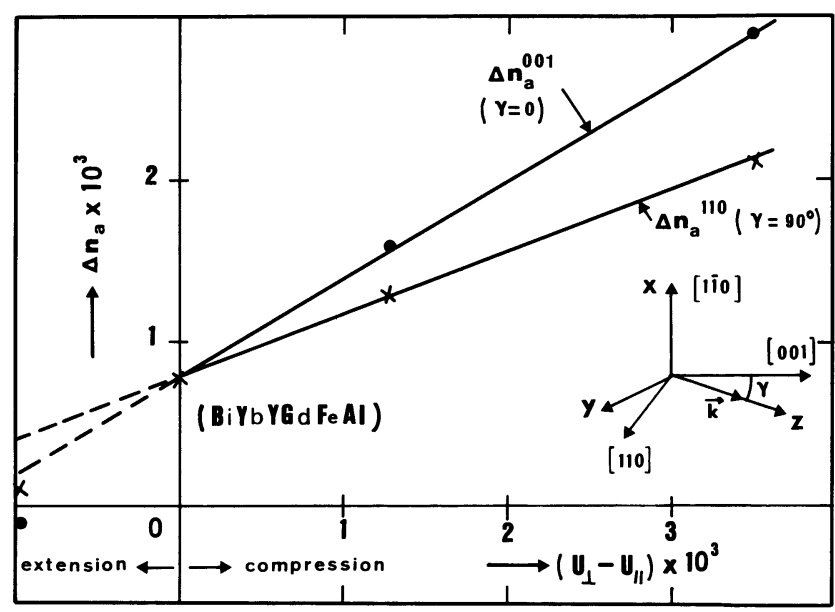

Fig. 3. - Deformation dependence of the anisotropic birefringence $\Delta n_{\mathrm{a}}$ in (110)-oriented films.

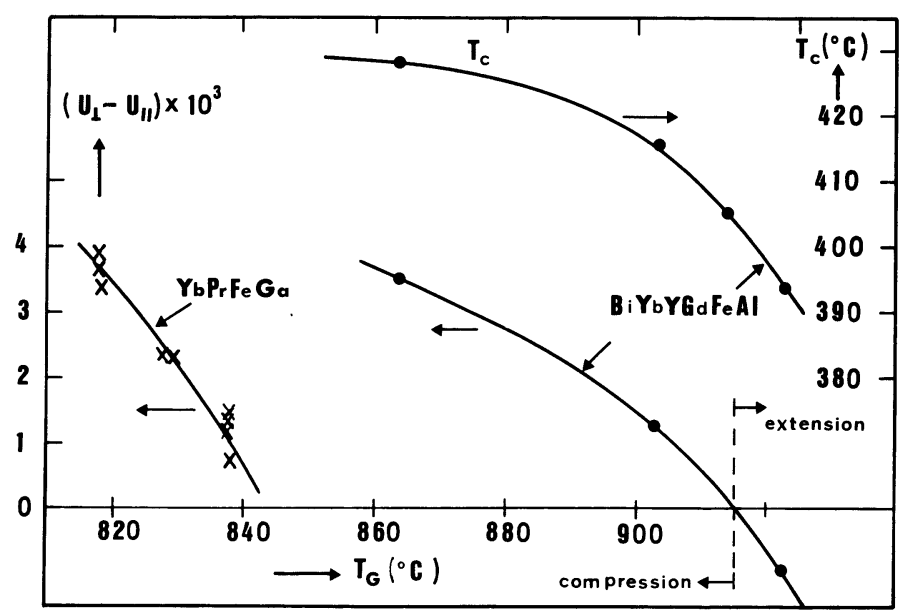

Fig. 4. - Growth temperature dependences of films deformation and Curie temperature. 
Therefore the accuracy for $\left(u_{\perp}-u_{\|}\right)$is better than $3 \times 10^{-5}$. For each chemical system the films were grown from the same melt solution at different $T_{\mathrm{G}}$ which corresponds to different compositions and film deformations. A light beam at 1.15 micron wavelength produced by an He-Ne laser was introduced into the films by using the prism method [5]. The angles of the incident light on the prism face, which depend on the excited $m$-order mode, were measured. Modes were excited under constant coupling value which implies that the optical gap between the film and the prism was taken into consideration for calculation in accordance with the method used in [6]. From the equations of the wave-guided propagation of light in anisotropic media [7], the refractive indices were determined for TE and TM mode separately and the effective phase mismatch or optical birefringence deduced from their difference $\Delta n_{\mathrm{e}}=\left(n_{\mathrm{TM}}-n_{\mathrm{TE}}\right)$ with accuracy better than one part to $10^{4}$.

The anisotropic birefringence $\Delta n_{\mathrm{a}}$ is deduced from equation (1) since the isotropic term $\Delta n_{\mathrm{i}}$ can be calculated. As shown on figures 2 and 3, $\Delta n_{\mathrm{a}}$ presents linear dependences on film deformation $\left(u_{\perp}-u_{\|}\right)$.

The birefringence has anisotropic behaviour in (110)-oriented film (Fig. 3) since it depends on light propagation direction in the film plane. That is not the case in (111)-oriented films since it was found not to depend, in the experimental limits, on light direction. As seen in figure 2 the experimental points for $\mathrm{YbPrFe}$ Ga-garnet system fit well a straight line going through the co-ordinate origin. Data are reported, for comparison, from results obtained in pure YIG and some rare-earth $(\mathrm{Tb}, \mathrm{Gd}, \mathrm{Eu})$-substituted YIG films grown previously on (111)-GGG substrates [7, 8].

In (110)-oriented Bi-based film under compression $\left(u_{\perp}-u_{\|}>0\right) \Delta n_{\mathrm{a}}$ presents different linear dependences on deformation when light is propagating along [001] and [110] direction. The straight lines are not going through the coordinate origin and cut equal segments on the ordinate axis which points to the presence of a non-photoelastic contribution to the birefringence. Strong deviation from linearity is observed in extension region $\left(u_{\perp}-u_{\|}<0\right)$ and will be discussed later.

\section{Discussion.}

Two contributions to $\Delta n_{\mathrm{a}}$ are known to be independent on deformation : the magnetooptical one or CottonMouton effect which is of the second order in magnetization components and the growth-induced one as observed recently by Ando et al. in (111)-oriented Bibased iron garnet films [9]. The greatest linear magnetic birefringence at room temperature and 1.15 micron wavelength amounts from $10^{-5}$ to $10^{-4}\left(\Delta n_{\mathrm{CM}}=\right.$ $6.5 \times 10^{-5}$ in pure YIG) which is between one and two orders of magnitude less than the birefringence measured in our Bi-ferrimagnetic films having zero deformation. Applied magnetic field up to $3 \mathrm{kOe}$ did not change the value of $\Delta n_{\mathrm{a}}$, so we can conclude that the main contribution from non-photoelastic effects to the birefringence arises from a growth-induced birefringence $\left(\Delta n_{\mathrm{a}} \simeq \Delta n_{\sigma}+\Delta n_{\mathrm{G}}\right)$.

- STRESS-INDUCED BIREFRINGENCE. - In (111)-films the stress-induced birefringence is described from the photoelastic constant $P_{44}$ by the relation :

$$
\Delta n_{\sigma}=n_{0}^{3} P_{44}\left(u_{\perp}-u_{\|}\right)
$$

where $n_{0}$ is the refractive index from isotropic films $\left(n_{x} \sim n_{y} \sim n_{z} \sim n_{0}\right)$. If dependences in non-deformed films of $n_{0}$ and $P_{44}$ on composition are small, direct proportionality of $n_{\mathrm{e}}$ on deformation can be expected as really observed from experiment in $\mathrm{YbPrFeGa}$ system with $P_{44}$ value equal to $-0.052 \pm 0.005$ [10]. From data obtained previously in YIG : TbAl, YIG : GdGa, and YIG : EuAl [7, 8] similar proportionality is obtained with $P_{44}=-0.045 \pm 0.005$. This smaller value can be explained from the different experimental procedures used for their determination. As a whole $P_{44}$ values obtained from our wave-guided measurements agree with those obtained by other methods [11-13].

This deformation increases by decreasing the growth temperature (Fig. 4) due to the segregation coefficient which becomes higher for the large ions as $\mathrm{Bi}^{3+}, \mathrm{Gd}^{3+}$, $\mathrm{Pr}^{3+}$ and becomes lower for the small ions as $\mathrm{Al}^{3+}$ and $\mathrm{Ga}^{3+}$. Therefore, by decreasing $T_{\mathrm{G}}$ the content of large ions increases which induces an increase of the deformation $\left(u_{\perp}-u_{\|}\right)$from extension to compression with a sign change at $T_{\mathrm{G}}=915^{\circ} \mathrm{C}$ for the Bi-YIG films. The dependence of the segregation coefficient on $T_{G}$ explains also an increase of the Curie temperature at low $T_{\mathrm{G}}$ due to the lower content of $\mathrm{Al}^{3+}$ ions in the ferric sites and the higher content of $\mathrm{Bi}^{3+}$ in the dodecahedral sites which stimulates the super-exchange field in the garnets [14].

The photoelastic contribution to $\Delta n_{\mathrm{a}}$ in (110)-films can be described for light propagating along the [001] and [110] directions by :

$$
\left.\begin{array}{l}
\Delta n_{\sigma}[001]=-n_{0}^{3} P_{44}\left(u_{\perp}-u_{\|}\right) \\
\Delta n_{\sigma}[110]=-n_{0}^{3}\left(P_{44}+\frac{\Delta P}{4}\right)\left(u_{\perp}-u_{\|}\right)
\end{array}\right\}
$$

with $\Delta P=P_{11}-P_{12}-2 P_{44}$.

From data of figure 3 the photoelastic coefficients in (110)-film are deduced such as : $P_{44}=0.059 \pm 0.005$, $\Delta P=+0.085 \pm 0.005$ and $P_{11}-P_{12}=-0.083 \pm$ 0.05 .

- GROWTH-INDUCED BIREFRINGENCE. - The origin of the strain independent contribution to the birefringence has to be connected to non-cubic distortion of film crystal lattice induced during the growth process as observed previously in bulk TbIG by Dillon $e t$ al. [15]. It is known that such distortions are at the origin of the growth-induced uniaxial magnetic anisotropy $K u^{\mathbf{G}}$ in (111)- and (110)-oriented epitaxial garnet films 


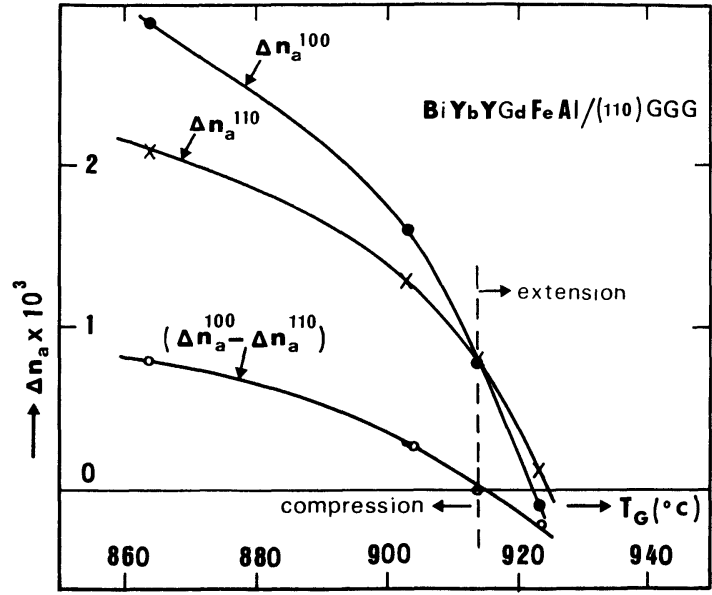

Fig. 5. - Growth temperature dependences of anisotropic birefringences in (110)-oriented films.

as used for magnetic bubble stability. On the other hand a magnetocrystalline orthorhombic anisotropy $K o$ has been observed in Bi-based (110)-oriented film only [10], similarly to the anisotropic behaviour for light propagation in our (110)-oriented film as shown in figure 3 with $\Delta n_{\mathrm{a}}[001] \neq \Delta n_{\mathrm{a}}[110]$.

The linear dependence of the birefringence on deformation has to mean that the magnitude of $\Delta n_{\mathrm{G}}$ is independent on $T_{\mathrm{G}}$. There is no data to our knowledge on the behaviour of optical anisotropy when $T_{G}$ is changing but the growth-induced magnetic anisotropy is known to decrease sharply when sufficiently high $T_{\mathrm{G}}$ is used. If it is assumed that $\Delta n_{\mathrm{G}}$ behaves similarly, one can explain the deviations from linearity for Bi-substituted films grown at the highest $T_{\mathrm{G}}=$ $932{ }^{\circ} \mathrm{C}$ (extension region in Fig. 3).

The (111)-oriented $\mathrm{YbPrFeGa}$ films has a strong growth-induced magnetic anisotropy of easy-plane type as indicated by their magnetization saturation fields parallel $(\sim 10 \mathrm{Oe})$ and perpendicular $(\sim 10 \mathrm{kOe})$ to their plane independently of the sign of the deformation [16]. It is noteworthy that high $K u^{\mathbf{G}}$ values are not followed in these compounds by appearance of noticeable $\Delta n_{\mathrm{G}}$. From the tensor of growth-induced anisotropy one can obtain an expression for birefringence in (111)-oriented films such as :

$$
\begin{aligned}
\Delta n_{\mathrm{G}}\left(\gamma_{1} \gamma_{2} \gamma_{3}\right)= & \\
=\frac{\Delta C}{2 n_{0}}\left[2 R_{44} \gamma_{1}^{2}+\right. & \left(R_{12}-R_{11}+\frac{5}{6} \Delta R\right) \gamma_{2}^{2}+ \\
& \left.+\frac{\Delta R}{6} \gamma_{3}^{2}+\frac{\sqrt{2}}{3} \Delta R \gamma_{1} \gamma_{2}\right]
\end{aligned}
$$

with $\Delta R=R_{11}-R_{12}-2 R_{44}$, where $\Delta C$ is the difference of rare-earth ions concentration in nonequivalent dodecahedral positions, $\gamma_{\mathrm{i}}$ are direction cosines of the direction of crystal growth and $R_{\mathrm{ij}}$ are constants of growth-induced anisotropy tensor. For a crystal growth along [111] direction $\left(\gamma_{1}=1 ; \gamma_{2}=\right.$ $\gamma_{3}=0$ ) Equation (4) is reduced to $\Delta n_{G}=R_{44} \Delta C$ and this quantity must be equal or close to zero in accordance with experiment. The fact that $K u^{\mathbf{G}} \neq 0$ implies $\Delta C \neq 0$ and therefore it is conclude that $R_{44}=0$ in our (111)-oriented films.

In (110)-oriented films the growth-induced birefringence is described for light propagating along the [001] and [110] directions by :

$$
\left.\begin{array}{l}
\Delta n_{\mathrm{G}}[001]=n_{0}^{-1} R_{44}\left(\gamma_{1}^{2}-\gamma_{2}^{2}\right) \Delta C \\
\Delta n_{\mathrm{G}}[110]=n_{0}^{-1}\left(R_{44}+\frac{\Delta R}{4}\right)\left(\gamma_{1}^{2}-\gamma_{2}^{2}\right) \Delta C
\end{array}\right\}
$$

It is observed from experiment equal values of $\Delta n_{G}$ independently of the light propagation direction in the film, which requires $\Delta R=0$. The dependence of $\Delta n_{\mathrm{a}}$ [001]- $\Delta n_{\mathrm{a}}$ [110] on deformation in (110)-film is given in figure 6. Since $\Delta n_{\mathrm{G}}$ is isotropic, such a difference is associated only with photoelasticity and therefore the absence of deviation from linearity in region of film extension supports the hypothesis made above concerning the decrease of $\Delta n_{\mathrm{G}}$ when $T_{\mathrm{G}}$ is going up to the melt saturation temperature.

\section{Conclusion.}

From optical wave-guide investigation methods it has been possible to separate the main contributions to the anisotropic modes phase-mismatch associated with stress-induced and growth-induced birefringences. In (110)-oriented Bi-based films the stress-induced birefringence has anisotropy similar to the magnetic orthorhombic anisotropy observed in these compounds.

\section{Acknowledgment.}

One of the authors (H. L. G.) grateful acknowledge Dr. K. Ando from Electrotechnical Laboratory (Ibaraki, Japan) for fruitful discussion on wave guide optics.

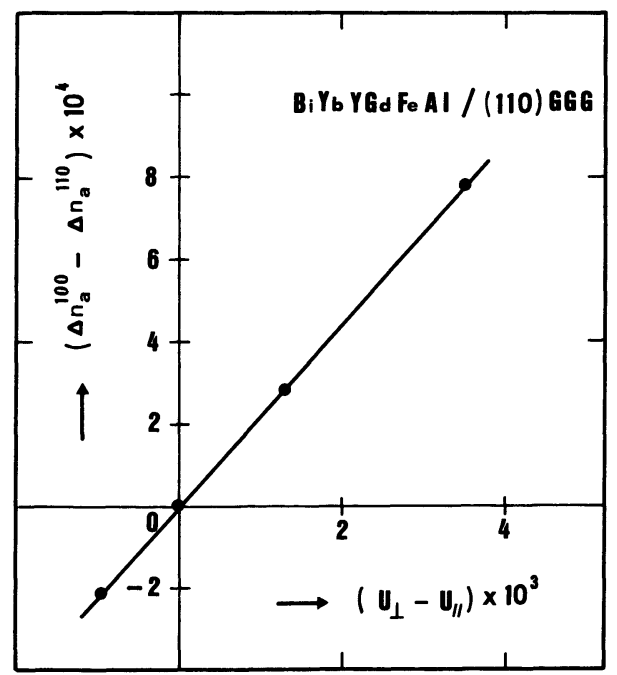

Fig. 6. - Deformation dependence of the birefringence anisotropy $\Delta n_{\mathrm{a}}[100]-\Delta n_{\mathrm{a}}[110]$ in (110)-oriented film. 


\section{References}

[1] YARIV, A., IEEE J. Quantum Electron. QE-9 (1973) 919.

[2] Castera, J. P., Proc. Intermag Conf. Hamburg, (paper BB-02), 1984.

[3] Hepner, G., Castéra, J. P. and Désormière, B., AiP Conf. Proc. 29 (1976) 658.

[4] Courtois, L., Desvignes, J. M., Torfeh, M., Le Gall, H. and Castéra, J. P., Proc. of Rare Earth Conf., Olgebay Park USA, (1977).

[5] Ulrich, R., TORge, R., Appl. Opt. 12 (1973) 2901.

[6] Ageev, A. N., Mokruchnia, E. V., Trifonov, A. S., J. Theor. Phys. 52 (1982) 2044.

[7] Castéra, J. P., Thesis, Orsay (1977).

[8] ToRfeh, M., Desvignes, J. M., Le Gall, H., 9th ICMFS Booklet Univ. Lodz, p. 127 (1979).

[9] ANdo, K., Koshizuka, N., OKuda, T. and YokayaMA, Y., Japan J. Appl. Phys. 22 (1983) L618.
[10] Ageev, A. N., Mokruchnia, E. V., Rutkin, O. G., J. Theor. Phys. Lett. 9 (1983) 328.

[11] LYNCh, R. T., Dillon, J. F., VAN UiterT, L. C., J. Appl. Phys. 44 (1973) 225.

[12] Pisarev, R. V., Koananova, N. N., Tidove, A. G., Dachevskaïa, L., Phys. Tverg. Tela 17 (1975) 56.

[13] Dedoukh, L. M., Nikitenko, V. J., Phys. Tvergodo Tela 12 (1970) 1768.

[14] Geller, S., Williams, H. J., Espinosa, G. P., Sherwood, R. C., Gilleo, M. A., Appl. Phys. Lett. 3 (1963) 21.

[15] Dillon, J. F. Jr., Gyorgy, E. M. and Remeika, J. P., A.I.P. Conf. Proc. 5 (1971) 190.

[16] Daval, J., Ferrand, B., Geynet, J., Challeton, D., Peuzin, J. C., Mat. Res. Bull. 10, 1975, 95. 